\title{
Leptin stimulates pituitary prolactin release through an extracellular signal-regulated kinase-dependent pathway
}

\author{
Christian K Tipsmark, Christina N Strom, Sean T Bailey and Russell J Borski \\ Department of Zoology, North Carolina State University, Raleigh, North Carolina 27695-7617, USA \\ (Correspondence should be addressed to C K Tipsmark who is now at Institute of Biology, University of Southern Denmark, Campusvej 55, DK-5230 Odense M, \\ Denmark; Email: ckt@biology.sdu.dk)
}

\begin{abstract}
Leptin was initially identified as a regulator of appetite and weight control centers in the hypothalamus, but appears to be involved in a number of physiological processes. This study was carried out to examine the possible role of leptin in regulating prolactin (PRL) release using the teleost pituitary model system. This advantageous system allows isolation of a nearly pure population of lactotropes in their natural, in situ aggregated state. The rostral pars distalis were dissected from tilapia pituitaries and exposed to varying concentrations of leptin $(0,1,10,100 \mathrm{nM})$ for $1 \mathrm{~h}$. Release of PRL was stimulated by leptin in a potent and concentration-dependent manner. A time-course experiment showed that the strongest response in PRL release with leptin occurs within the first hour (approximately sixfold), and stimulation was sustained after $16 \mathrm{~h}$ (approximately twofold). Many of the actions of
\end{abstract}

leptin are mediated by the activation of extracellular signalregulated kinase (ERK1/2) but nothing is known about the cellular mechanisms by which leptin might regulate PRL secretion in vertebrates. We therefore tested whether ERK1/2 might be involved in the leptin PRL response and found that the ERK inhibitor, PD98059, hindered leptininduced PRL release. We further analyzed leptin response by quantifying tyrosine and threonine phosphorylation of ERK1/2 using western blots. One hour incubation with leptin induced a concentration-dependent increase in phosphorylated, and thus active, ERK1/2. Our data show that leptin is a powerful stimulator of in vitro PRL release and that its actions occur in part through stimulation of ERK1/2. Journal of Endocrinology (2008) 196, 275-281

\section{Introduction}

Among the pituitary hormones, prolactin (PRL) is the most versatile in the spectrum and number of functions it regulates. PRL modulates virtually every aspect of vertebrate physiology, including osmoregulation, growth, metabolism, development, reproduction, parental behavior, and immune function (Freeman et al. 2000). The central biological importance of PRL highlights the need for defining those factors and intracellular mechanisms that govern its secretion from the pituitary gland. Among its numerous functions, PRL plays a critical role in freshwater osmoregulation (Manzon 2002) as well as in the modulation of energy metabolism in teleost fishes (Sheridan 1986, Leena et al. 2001, Sangio-Alvarellos et al. 2006). PRL is regulated by a complex array of hormonal factors and neurotransmitters, including the osmoregulatory and metabolic hormones, insulin-like growth factor-I (IGF-I), and cortisol (Nishioka et al. 1988, Fruchtman et al. 2000, Hyde et al. 2004). Gut stomach-derived ghrelin also modulates teleost PRL release (Riley et al. 2002, Kaiya et al. 2003a) and in mammals this hormone may act in cooperation with leptin to transfer information to the brain about the caloric state of the animal (Popovic \& Duntas 2005).
Leptin is the $16 \mathrm{kDa}$ product of the ob gene, and the hormone is primarily expressed and secreted by white adipose tissue in mammals (Zhang et al. 1994). In teleosts, putative leptin has been detected with mammalian antibodies and is particularly abundant in the bloodstream and liver (Johnson et al. 2000). Recently, a teleost ortholog of mammalian leptin was found in three fish species (Kurokawa et al. 2005) and shown to be expressed in various tissues including liver and adipose (Kurokawa et al. 2005, Huising et al. 2006a). Leptin receptors are also present in the genome of teleosts examined thus far (Huising et al. 2006b).

Since its discovery, the biology of leptin has been extensively studied and in mammals it seems important as a humoral 'lipostat', by increasing energy expenditure and decreasing appetite (Sahu 2004). Accordingly, food intake is suppressed in response to treatment with exogenous leptin in mammals (Campfield et al. 1995, Sahu 2004) and birds (Denbow et al. 2000, Lohmus et al. 2003). In fish some ambiguity exist as to leptin's role, since treatment with mammalian hormone was reported to have either anorexigenic actions (sunfish, Johnson et al. 2000; goldfish, Volkoff et al. 2003), or no effect at all (catfish, Silverstein \& Plisetskaya 2000; coho salmon, Baker et al. 2000; sunfish, Londraville \& Duvall 2002). Food deprivation in 
mammals induces a drop in leptin expression (Bertile et al. 2003) but a similar treatment elicits little effect in carp (Huising et al. 2006a), suggesting possible evolutionary differences in leptin regulation among endotherms and ectotherms.

In mammals it appears that leptin works on hypothalamic neurons to induce luteinizing hormone release, and when energy stores are sufficient, promotes the initiation of sexual maturation (Smith et al. 2002, Harvey \& Ashford 2003). Leptin treatment also stimulates circulating PRL levels in rats (Gonzalez et al. 1999, Watanobe 2002). Melanocortin-4 receptor antagonists decrease the magnitude of leptin-induced PRL surges in vivo indicating interaction with this receptor and that hypothalamic control of the rat pituitary plays a significant role in the response (Watanobe et al. 1999). In addition to leptin's effect via the hypothalamus, leptin appears to act directly at the level of the rat pituitary to stimulate gonadotropin and PRL release from anterior pituitary cells (Yu et al. 1997). Leptin also stimulates PRL secretion from bovine pituitary explants (Accorsi et al. 2007), but has no effect on PRL release from primary cultures of porcine anterior pituitary cells (Nonaka et al. 2006). Whether leptin stimulates PRL release in nonmammalian vertebrates is unknown. In isolated pituitary cells from teleosts, recombinant mammalian leptin induces release of gonadotropins (European sea bass, Peyon et al. 2001; rainbow trout, Weil et al. 2003) and somatolactin (Peyon et al. 2003). We examined whether leptin might modulate PRL secretion from the teleost pituitary, which contains a naturally, highly enriched population of lactotropes within the rostral pars distalis (RPD, Nishioka et al. 1988, see Fruchtman et al. 2000, Kasper et al. 2006). The pituitary RPD, containing 95-99\% PRL cells, can be easily isolated and allows the study of a nearly pure population of PRL cells in their naturally aggregated in situ state using completely defined, hormone-free culture medium. We characterized the concentration-dependent response and timecourse of leptin's possible effect on PRL release from the RPD. Extracellular signal-regulated protein kinases (ERK1/2) have been reported to be essential signal transducers of leptin responses in several tissues (Harvey \& Ashford 2003) and it is involved in IGF-I induced PRL release from the teleost lactotrope (Fruchtman et al. 2000, 2001). Whether this signaling pathway might be involved in mediating potential actions of leptin on PRL release in vertebrates is unknown. To this end, we examined if the selective blockage of ERK1/2 activation might alter PRL release evoked by leptin and whether leptin might regulate the phosphorylation, and thus activation of ERK1/2 within the teleost RPD.

\section{Materials and Methods}

\section{Static incubations}

Adult male tilapia (Oreochromis mossambicus; $100-200 \mathrm{~g}$ ) were maintained in freshwater at a constant photoperiod $(12 \mathrm{~h}$ light: $12 \mathrm{~h}$ darkness) for a minimum of 3 weeks prior to all experiments. Fish were killed by decapitation, the RPD was dissected from the pituitary and placed in separate wells of a
Falcon 96-well plate (Becton Dickinson, Oxnard, CA, USA) containing $100 \mu \mathrm{l}$ Krebs bicarbonate Ringers. Ringers solution contained glucose, glutamine and Eagle's minimal essential medium (355-360 mOsm, pH 7·2; Hyde et al. 2004). Tissues were incubated at $27^{\circ} \mathrm{C}$ in a humidified chamber $\left(95 \% \mathrm{O}_{2} / 5 \%\right.$ $\mathrm{CO}_{2}$ ). The chamber was continuously agitated on a gyratory platform at 60 r.p.m. To allow PRL release to stabilize to baseline levels, the tissues were pre-incubated for $2 \mathrm{~h}$, after which, medium was removed and replaced with treatment medium. Samples were taken after 1, 4, and $16 \mathrm{~h}$, and medium and tissue were collected. Tissues were sonicated in RIA buffer $\left(0 \cdot 01 \mathrm{M}\right.$ sodium phosphate, $1 \% \mathrm{BSA}, 0 \cdot 01 \% \mathrm{NaN}_{3}$, and $0 \cdot 1 \%$ Triton X-100; $\mathrm{pH} 7 \cdot 3$ ) and stored at $-20^{\circ} \mathrm{C}$. For measures of ERK1/2, tissues were directly placed into reducing sample buffer for subsequent western blot analyses.

\section{PRL measurements}

The tilapia pituitary releases two PRLs ( $\mathrm{PRL}_{177}$ and $\mathrm{PRL}_{188}$ ) and both are regulated in a similar fashion by all secretagogue examined to date (see Hyde et al. 2004). Thus, in the present study only the release of the more abundant $\mathrm{PRL}_{188}$ was measured in a concentration-response and time-course experiment. Tilapia $\mathrm{PRL}_{188}$ was quantified using a homologous RIA as previously described (Ayson et al. 1993, Tipsmark et al. 2005) and hormone release is expressed as a percentage of the total amount of hormone in the incubations (tissue + media). In a separate experiment, the effect of a specific ERK1/2 inhibitor, PD98059, on leptin-induced PRL release was examined. In this experiment, PRL was quantified by colorimetric gel detection according to our previously described and validated procedures where both tilapia PRLs, due to their differences in sizes, could be measured simultaneously (Borski et al. 1991, Hyde et al. 2004). In short, tissue and media samples were run on SDSPAGE and the gels stained with Coomassie brilliant blue. After destaining, both $\mathrm{PRL}_{177}$ and $\mathrm{PRL}_{188}$ bands were quantified using an Odyssey scanner (LI-COR, Lincoln, NE, USA). Data were calculated as percentage of total hormone released or the amount of hormone released in media divided by total hormone (media + tissue) in the incubation.

\section{ERK1/2 analysis}

Tissues were sonicated in reducing sample buffer (NuPAGE, Invitrogen; final concentration in the loaded samples in mmol/l: 141 Tris base, 106 Tris $\mathrm{HCl}, 73$ LDS, 0.5 EDTA, 50 1,4-dithiothretiol and $8 \%$ glycerol (v/v), 0.019\% Serva blue $\mathrm{G} 250(\mathrm{w} / \mathrm{v}), 0 \cdot 006 \%$ phenol red $(\mathrm{w} / \mathrm{v}))$, and frozen at $-20{ }^{\circ} \mathrm{C}$ before western analysis. After heating at $80^{\circ} \mathrm{C}$ for $10 \mathrm{~min}$, proteins were resolved by SDS-PAGE. Proteins were separated by gel electrophoresis using $4-12 \%$ Bis-Tris gels (NuPAGE), and MES/SDS-buffer (in mmol/1: 50 2-( $N$-morpholino)ethanesulfonic acid, 50 Tris, 3.5 SDS, 1 Na2-EDTA; with addition of NuPAGE antioxidant) at $200 \mathrm{~V}$ (Xcell II SureLock; Invitrogen). Molecular size was estimated by including 
a pre-stained marker (Bio-Rad). Following electrophoresis, the gel was soaked for $30 \mathrm{~min}$ in transfer buffer (in mmol/l: 25 Tris, 192 glycine and 20\% methanol) and immunoblotted onto nitrocellulose membranes $(0.45 \mu \mathrm{m}$; Invitrogen) by submerged blotting for $1 \mathrm{~h}$ at $30 \mathrm{~V}$ (XCell II; Invitrogen). Membranes were blocked in TBS-T with LI-COR blocking buffer (1:1) and washed in TBS-T.

For detection of dual phosphorylated (active) ERK1/2, monoclonal phospho-p44/42 MAPK (Thr202/Tyr204) from Cell Signaling was used (Beverly, MA, USA; dilution 1:2000). For detection of total ERK1/2, membranes were probed with polyclonal anti-MAPK (sc-94; Santa Cruz Biotechnology, Santa Cruz, CA, USA; dilution 1:1000). Following washing, membranes were incubated $1 \mathrm{~h}$ with goat anti-mouse and anti-rabbit secondary antibodies conjugated to Alexa IRDye 680 or IRDye $800 \mathrm{CW}$ (LI-COR). Phosphorylated and total (nonphosphorylated and phosphorylated) ERK1/2 was detected on the same blot at 680 and $800 \mathrm{~nm}$ respectively. Active (dual phosphorylated) ERK1 and ERK2 were normalized to total ERK1 and ERK2 content. Blotted proteins were detected and quantified using the Odyssey infrared imaging system (LI-COR).

\section{Statistical analysis}

Statistical differences were analyzed using Statistica 7.0 (Tulsa, OK, USA). When appropriate, one-way ANOVA in conjunction with Dunnett's test or two tailed $t$-test were used to analyze differences among treatment groups. In all cases, a significance level of $P=0 \cdot 05$ was used.

\section{Results}

\section{Effect of leptin on PRL release}

We tested the hypothesis that leptin may modulate PRL release directly at the level of the pituitary by first testing the possible effect of a range of leptin concentrations $\left(10^{-9}-10^{-7} \mathrm{M}\right)$ on in vitro $\mathrm{PRL}_{188}$ release from isolated RPDs. As shown in Fig. 1, leptin stimulates $\mathrm{PRL}_{188}$ release many fold over basal levels (basal release: $0 \cdot 57 \pm 0 \cdot 12 \%$ of total content) during 1 -h incubation. The effect was concentration dependent with $10^{-9}-10^{-7} \mathrm{M}$ dosages stimulating $\mathrm{PRL}_{188}$ release by four- to sevenfold. We also evaluated the time-course over which leptin stimulates $\mathrm{PRL}_{188}$ release, using a $10^{-8} \mathrm{M}$ leptin concentration. As shown in Fig. 2, leptin stimulates $\mathrm{PRL}_{188}$ release by $600 \%$ over the first hour (basal release: $1 \cdot 17 \pm 0 \cdot 23 \%$ ) of incubation, with a more modest increase in $\mathrm{PRL}_{188}$ release during longer-term incubations (1-4 h, 220\%, $P=0 \cdot 08$, basal release: $3 \cdot 09 \pm 0 \cdot 90 \%$; 4-16 h, $160 \%, P<0 \cdot 05$, basal release: $21 \cdot 53 \pm 2 \cdot 77 \%)$.

\section{Effect of an ERK1/2 blocker on leptin-induced PRL release}

The role of ERK in transducing leptin's effect in the RPD was examined using PD98059, which blocks the activation of

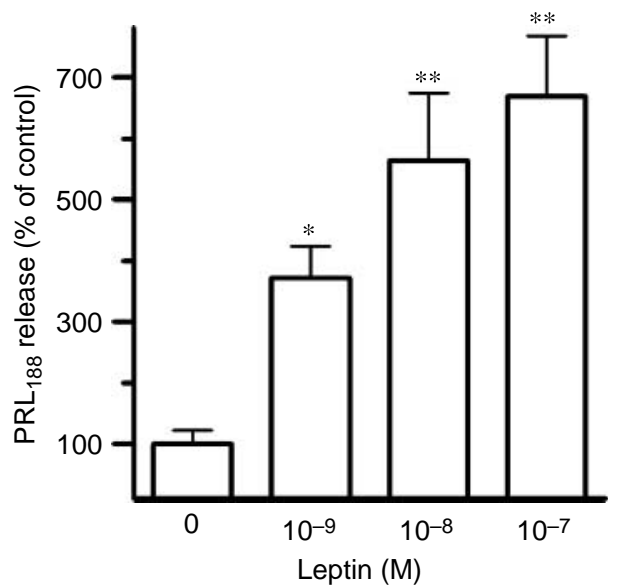

Figure 1 Effect of different concentrations of leptin on $\mathrm{PRL}_{188}$ release from lactotropes in isolated RPDs during 1-h incubation. Values are means \pm s.E.M. $(n=10)$. Asterisks indicate significant difference from control $\left({ }^{* *} P<0 \cdot 01 ; * P<0 \cdot 05\right)$.

ERK1 and ERK2 by inhibiting ERK kinase (MEK). As shown in Fig. 3, the two concentrations of PD98059 (3 and $30 \mu \mathrm{M})$ examined were both effective in suppressing the stimulatory actions of leptin on the release of both PRLs during a 4-h incubation $\left(\mathrm{PRL}_{177}\right.$ basal release: $3 \cdot 92 \pm 0 \cdot 48 \%$; PRL $_{188}$ basal release: $\left.4 \cdot 70 \pm 0 \cdot 93 \%\right)$.

\section{Effect of leptin on ERK1/2 phosphorylation}

Whether the leptin-induced increase in PRL secretion might be linked to an increase in ERK signaling was further assessed by quantifying changes in dual phosphorylation, and thus activity of ERK1/2. Tilapia RPDs were treated with different concentrations of leptin for $1 \mathrm{~h}$ and the samples were analyzed using double fluorescent western blotting techniques. In Fig. 4, western blotting using the ERK1/2 specific antibody and an antibody specific to the dual phosphorylated kinase revealed two protein bands of $47 \mathrm{kDa}$ (ERK1) and $43 \mathrm{kDa}$ (ERK2). In Fig. 4A the dual phosphorylated epitope

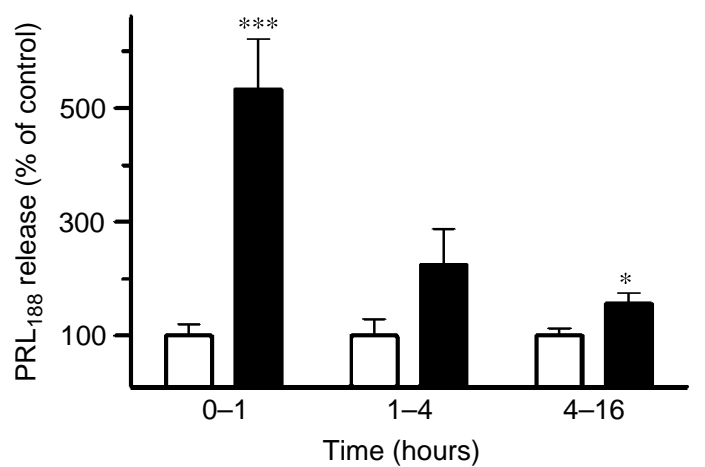

Figure 2 Time-course effects of leptin $(10 \mathrm{nM})$ on $P R L_{188}$ release from lactotropes in isolated RPDs (control media, open bars; leptin, closed bars). Values are means \pm s.E.M. $(n=10)$. Asterisks indicate significant difference from control $(* * * P<0 \cdot 001 ; * P<0 \cdot 05)$. 

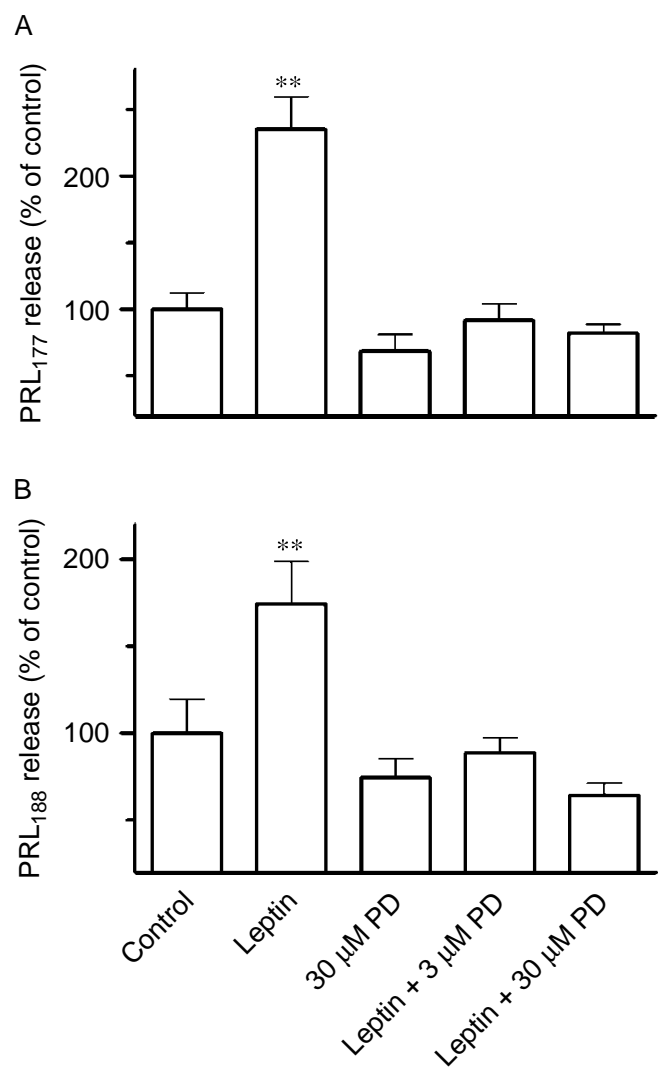

Figure 3 Effects of the specific MEK inhibitor, PD98059, on leptin induced $\mathrm{PRL}_{177}(\mathrm{~A})$ and $\mathrm{PRL}_{188}(\mathrm{~B})$ release from lactotropes in isolated RPDs. Values are means \pm s.E.M. $(n=7)$. Asterisks indicate significant difference from control $(* * P<0 \cdot 01)$.

of ERK1 and ERK2 was detected at $700 \mathrm{~nm}$. In Fig. 4B, the total ERK1 and ERK2 was detected on the same blot at $800 \mathrm{~nm}$. The relative phosphorylated values normalized to the total ERK abundance are depicted as relative ERK1 and ERK2 activity in Fig. 5A and B. One-hour incubation with leptin induced more than twofold higher phosphorylation of ERK1/2 than that observed in the absence of hormone. The dose-dependent increase in ERK1/2 phosphorylation with leptin paralleled that observed with the PRL release response (PRL release and ERK1 activity: $r^{2}=0.9981, P=0.0010$. PRL release and ERK2 activity: $\left.r^{2}=0.9997, P=0 \cdot 0001\right)$. There were no significant changes in total (phosphorylated + nonphosphorylated) protein expression of ERK1 and ERK2 during the $1-\mathrm{h}$ incubation (Fig. 5C and D).

\section{Discussion}

The present data demonstrate that leptin is a potent stimulator of PRL release in teleosts and that its actions are mediated, at least in part, through stimulation of ERK1/2. Since its discovery (Zhang et al. 1994), research has mainly focused on leptin's actions on the brain in regulating appetite suppression
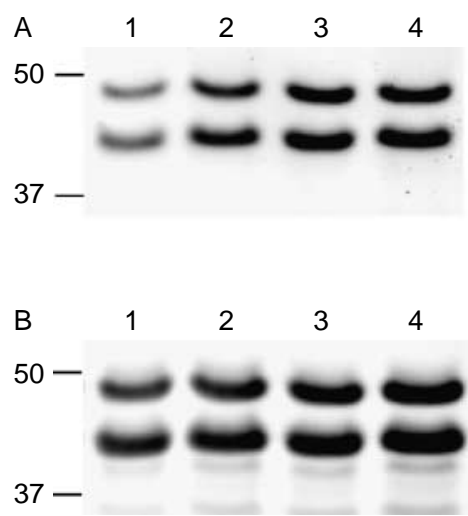

Figure 4 Western blot showing detection of double phosphorylated ERK1/2 (A) and total ERK1/2 (B) in RPDs treated for $1 \mathrm{~h}$ with control Ringer's (lane 1), 1 nM leptin (lane 2), $10 \mathrm{nM}$ leptin (lane 3), and $100 \mathrm{nM}$ leptin (lane 4). Bars designate molecular weight markers (kDa).

and thermogenesis (Sahu 2004). It is increasingly clear that leptin also plays important roles in control of neuroendocrine function (Smith et al. 2002) by stimulating pituitary hormone release in mammals either at the level of the pituitary or indirectly through regulation of the hypothalamus (Inui 1999, Watanobe 2002). Likewise, leptin receptors are highly expressed in both the mammalian hypothalamus and pituitary (Jin et al. 2000, Czaja et al. 2002). In isolated anterior pituitaries from rats, nanomolar concentrations of leptin stimulate gonadotropin release (Yu et al. 1997). In teleosts, mammalian leptin in the micromolar range has been shown to induce gonadotropin release from dispersed pituitary cells (Peyon et al. 2001, Weil et al. 2003). The authors suggested that the apparent insensitivity of the cells to nanomolar concentration of leptin could be explained by the use of heterologous human and mouse hormone respectively. In addition to its effect on gonadotropes, leptin has also been shown to regulate release of $\mathrm{GH}$ and PRL from isolated adenohypophysis preparations in rodents and cows ( $\mathrm{Yu}$ et al. 1997, Zieba et al. 2003). In other vertebrates, data are largely lacking, although one study has shown that micromolar concentrations of leptin stimulate somatolactin release by sixfold during the initial hours of treatment in European sea bass (Peyon et al. 2003).

In the current study, we found leptin to be a very potent PRL secretagogue, inducing a sixfold initial increase in PRL release during the first hour followed by a lower sustained twofold elevation during $1-4$ and $4-16$ h of treatment. This temporal dynamics in PRL stimulation with leptin likely represents a classic biphasic response observed by many endocrine cells during stimulus-secretion coupling and is similar to that previously shown to occur with exposure to IGF-I, ghrelin, and angiotensin II in tilapia (Kajimura et al. 2002, Eckert et al. 2003, Kaiya et al. 2003b).

In contrast to the effects of mammalian leptin on teleost gonadotrope and somatolactotropes as mentioned above, we found that the tilapia lactotrope is highly sensitive to 
A

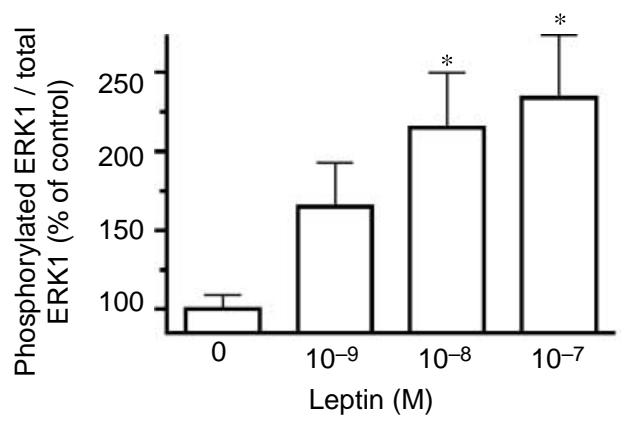

$\mathrm{C}$

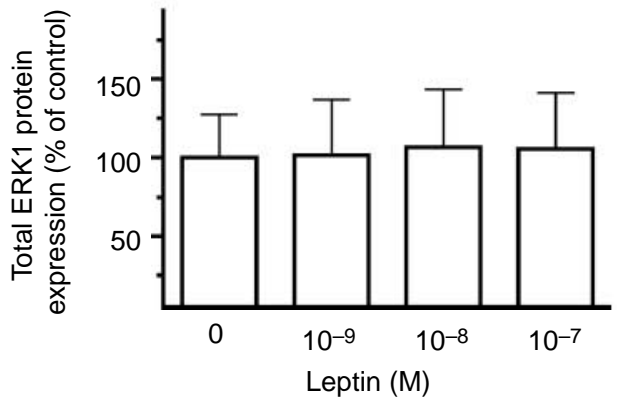

B

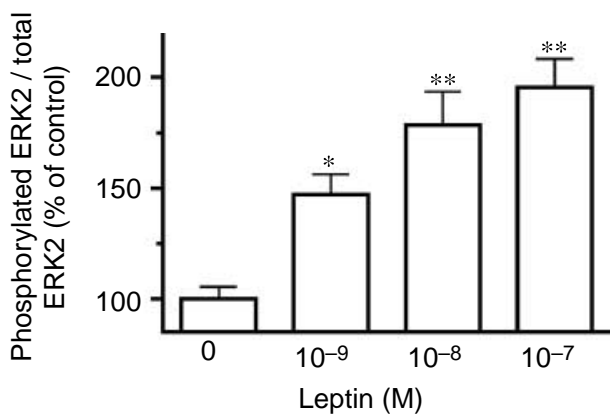

$\mathrm{D}$

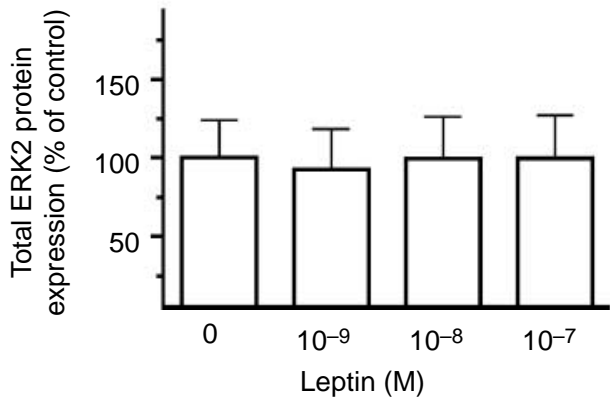

Figure 5 Effect of different concentrations of leptin on phosphorylation/activation of ERK1 (A) and ERK2 (B) during 1-h incubation. Dual phosphorylated (active) ERK1 (A) and ERK2 (B) normalized to total ERK1/2 in RPDs. Abundance of total ERK1 (C) and ERK2 (D) per RPD in the same experiment. Values are means \pm s.E.M. $(n=4)$. Asterisks indicate significant difference from control $\left(* * P<0 \cdot 01 ;{ }^{*} P<0 \cdot 05\right)$.

recombinant human leptin, responding to the hormone at low nanomolar concentrations. Our studies are in agreement with previous investigations on rat anterior pituitary cells and bovine pituitary explants where leptin also stimulates PRL secretion, albeit with less potency than that observed here (Yu et al. 1997, Accorsi et al. 2007). By contrast there was no effect of leptin on PRL release from porcine pituitary cells (Nonaka et al. 2006), suggesting potential species differences in responsiveness to leptin. The use of serum-supplemented medium prior to or during exposure to test compounds might also contribute to potential differences in responsiveness of lactotropes among studies. However, this is largely eliminated in the present investigations, where a nearly pure population of lactotropes was incubated in a completely defined medium. This reduces any confounding variables associated with exposure to undefined serum factors and the potential effects it may have on leptin regulation of PRL secretion. In the present study, the effect of leptin is most likely receptor mediated, since there is a clear concentration-dependent action of leptin on PRL release and ERK1/2 activation. Whether the actions of leptin on PRL release reflects a direct regulation of lactrotropes or is mediated by paracrine factors secreted from other pituitary cell types (adrenocorticotropin secreting or stellate cells in the RPD) is uncertain. Future studies co-localizing leptin receptors to lactotropes are required to address this question.
The effects of leptin observed in the present study appear physiologically relevant since the effective concentrations fall within circulating values measured in mammals (Accorsi et al. 2005) and that of the putative hormone measured in teleosts based on heterologous RIA (Mustonen et al. 2002, Nagasaka et al. 2006).

Leptin receptors belong to the cytokine receptor superfamily (Huising et al. 2006b) and the activation of JAK tyrosine kinase via the receptors intracellular signaling domain has been reported to stimulate several signal transduction pathways. Leptin receptor-driven signaling includes the JAKSTAT pathway, and both the PI 3-kinase and Ras-ERK pathways, both of which are downstream of JAK (Harvey \& Ashford 2003, Frühbeck 2006). In addition, we have previously found that the specific inhibitor of ERK activation, PD98059, blocks IGF-I evoked PRL release from striped bass RPDs (Fruchtman et al. 2001) and therefore PRL secretion can in some instances be controlled by this signaling kinase. In the current study, evidence suggests that that leptin-induced PRL release is dependent on ERK activation. The potent inhibitor of ERK, PD98059 was able to block leptin-induced PRL release. Additionally, we directly analyzed ERK1/2 activity by quantifying double tyrosine and threonine phosphorylation of ERK1/2, using western blotting and dual infrared imaging. One-hour 
incubation with leptin induced an increase in double phosphorylation, and thus activity, of ERK1/2. The concentration-response curve of leptin and RPD ERK1/2 activity corresponded well with that observed for leptin and PRL release, further suggesting leptin's actions are mediated by ERK activation.

In summary, findings demonstrate that leptin is a very potent in vitro secretagogue of PRL release in ectotherms and are the first to suggest in vertebrates that leptin stimulates PRL release through ERK1/2 activation. However, the physiological significance of leptin's actions in stimulating PRL release including any similar effects it may have on PRL secretion in vivo remains uncertain. Considering the multitude of actions of PRL and as yet the poorly defined role of leptin in teleosts, it is possible that leptin may interact with PRL to regulate metabolism, growth, osmotic homeostasis, or maturation. Since PRL has been shown to modulate lipid metabolism in teleosts (Sheridan 1986, Leena et al. 2001, Sangiao-Alvarellos et al. 2006), it is possible that leptin may alter PRL secretion to change fat deposition or other metabolic processes in fish. Because of the significant expression of the ghrelin gene in gill and kidney, it has been suggested that this appetite regulatory hormone could be involved in modulating the function of these osmoregulatory organs (Kaiya et al. 2003b). PRL is an essential hormone for freshwater osmoregulation in teleosts (Manzon 2002) and it is possible that leptin could interact with PRL in regulating osmotic homeostasis.

\section{Acknowledgements}

This research was supported by grants from the United States National Science Foundation (IBN-0215205) to R J B and a Postdoctoral Fellowship grant by The Carlsberg Foundation (2005-1-311) to C K T. The authors declare that there is no conflict of interest that would prejudice the impartiality of this scientific work.

\section{References}

Accorsi PA, Govoni N, Gaiani R, Pezzi C, Seren E \& Tamanini C 2005 Leptin, GH, PRL, insulin and metabolic parameters throughout the dry period and lactation in dairy cows. Reproduction in Domestic Animals $\mathbf{4 0}$ 217-223.

Accorsi PA, Munno A, Gamberoni M, Viggiani R, De Ambrogi M, Tamanini C \& Seren E 2007 Role of leptin on growth hormone and prolactin secretion by bovine pituitary explants. Journal of Dairy Science 90 1683-1691.

Ayson FG, Kaneko T, Tagawa M, Hasegawa S, Grau EG, Nishioka RS, King DS, Bern HA \& Hirano T 1993 Effects of acclimation to hypertonic environment on plasma and pituitary levels of two prolactins and growth hormone in two species of tilapia, Oreochromis mossambicus and Oreochromis niloticus. General and Comparative Endocrinology 89 138-148.

Baker DM, Larsen DA, Swanson P \& Dickhoff WW 2000 Long-term peripheral treatment of immature coho salmon (Oncorhynchus kisutch) with human leptin has no clear physiologic effect. General and Comparative Endocrinology 118 134-138.
Bertile F, Oudart H, Criscuolo F, Le Maho Y \& Raclot T 2003 Hypothalamic gene expression in long-term fasted rats: relationship with body fat. Biochemical and Biophysical Research Communications 303 1106-1113.

Borski RJ, Helms LMH, Richman NH \& Grau EG 1991 Cortisol rapidly reduces prolactin release and cAMP and $45 \mathrm{Ca}^{2+}$ accumulation in the cichlid fish pituitary in vitro. PNAS 88 2758-2762.

Campfield LA, Smith FJ, Guisez Y, Devos R \& Burn P 1995 Recombinant mouse $\mathrm{OB}$ protein: evidence for a peripheral signal linking adiposity and central neural networks. Science 269 546-549.

Czaja K, Lakomy M, Sienkiewicz W, Kaleczyc J, Pidsudko Z, Barb CR, Rampacek GB \& Kraeling RR 2002 Distribution of neurons containing leptin receptors in the hypothalamus of the pig. Biochemical and Biophysical Research Communications 298 333-337.

Denbow DM, Meade S, Robertson A, McMurtry JP, Richards M \& Ashwell C 2000 Leptin-induced decrease in food intake in chickens. Physiology and Behavior 69 359-362.

Eckert SM, Hirano T, Leedom TA, Takei Y \& Grau EG 2003 Effects of angiotensin II and natriuretic peptides of the eel on prolactin and growth hormone release in the tilapia, Oreochromis mossambicus. General and Comparative Endocrinology $130333-339$

Freeman ME, Kanyicska S, Lerant A \& Nagy G 2000 Prolactin: structure, function, and regulation of secretion. Physiological Reviews 80 1523-1631.

Fruchtman S, Jackson L \& Borski RJ 2000 Insulin-like growth factor I disparately regulates prolactin and growth hormone synthesis and secretion: studies utilizing the teleost pituitary model. Endocrinology 141 2886-2894.

Fruchtman S, Gift B, Howes B \& Borski RJ 2001 Insulin-like growth factor-I augments prolactin and inhibits growth hormone release through distinct as well as overlapping cellular signaling pathways. Comparative Biochemistry and Physiology 129 237-242.

Frühbeck G 2006 Intracellular signaling pathways activated by leptin. Biochemical Journal 393 7-20.

Gonzalez LC, Pinilla L, Tena-Sempere M \& Aguillar E 1999 Leptin $_{116-130}$ stimulates prolactin and luteinizing hormone secretion in fasted adult male rats. Neuroendocrinology 70 213-220.

Harvey J \& Ashford MLJ 2003 Leptin in the CNS: much more than a satiety signal. Neuropharmacology 44 845-854.

Huising MO, Geven EJW, Kruiswijk CP, Nabuurs SB, Stolte EH, Spanings FAT, Verburg-Van Kemenade BML \& Flik G 2006a Increased leptin expression in common carp (Cyprinus carpio) after food intake but not after fasting or feeding to satiation. Endocrinology 147 5786-5797.

Huising MO, Kruiswijk CP \& Flik G $2006 b$ Phylogeny and evolution of class-I helical cytokines. Journal of Endocrinology 189 1-25.

Hyde GN, Seale AP, Grau EG \& Borski RJ 2004 Cortisol rapidly suppresses intracellular calcium and voltage-gated calcium channel activity in prolactin cells. American Journal of Physiology 286 E626-E633.

Inui A 1999 Feeding and body-weight regulation by hypothalamic neuropeptides - mediation of the actions of leptin. Trends in Neuroscience 22 62-67.

Jin L, Zhang S, Burguera BG, Couce ME, Osamura RY, Kulig E \& Lloyd RV 2000 Leptin and leptin receptor expression in rat and mouse pituitary cells. Endocrinology 141 333-339.

Johnson RM, Johnson TM \& Londraville RL 2000 Evidence for leptin expression in fishes. Journal of Experimental Zoology 286 718-724.

Kaiya H, Kojima M, Hosoda H, Riley LG, Hirano T, Grau EG \& Kangawa K $2003 a$ Amidated fish ghrelin: purification, cDNA cloning in the Japanese eel and its biological activity. Journal of Endocrinology 176 415-423.

Kaiya H, Kojima M, Hosoda H, Riley LG, Hirano T, Grau EG \& Kangawa K $2003 b$ Identification of tilapia ghrelin and its effects on growth hormone and prolactin release in the tilapia, Oreochromis mossambicus. Comparative Biochemistry and Physiology, Part B 135 421-429.

Kajimura S, Uchida K, Yada T, Hirano T, Aida K \& Grau EG 2002 Effects of insulin-like growth factors (IGF-I and -II) on growth hormone and prolactin release and gene expression in euryhaline tilapia, Oreochromis mossambicus. General and Comparative Endocrinology 127 223-231.

Kasper RS, Shved N, Takahashi A, Reinecke M \& Eppler E 2006 A systematic immunohistochemical survey of the distribution patterns of $\mathrm{GH}$, prolactin, 
somatolactin, beta-TSH, beta-FSH, beta-LH, ACTH, and alpha-MSH in the adenohypophysis of Oreochromis niloticus, the Nile tilapia. Cell and Tissue Research 325 303-313.

Kurokawa T, Uji S \& Suzuki T 2005 Identification of cDNA coding for a homologue to mammalian leptin from pufferfish, Takifugu rubripes. Peptides $26745-750$.

Leena S, Shameena B \& Oommen OV 2001 In vivo and in vitro effects of prolactin and growth hormone on lipid metabolism in a teleost, Anabas testudineus (Bloch). Comparative Biochemistry and Physiology, Part B 128 761-766.

Lohmus M, Sundstrom LF, El Halawani M \& Silverin B 2003 Leptin depresses food intake in great tits (Parus major). General and Comparative Endocrinology $13157-61$.

Londraville RL \& Duvall CS 2002 Murine leptin injections increase intracellular fatty acid-binding protein in green sunfish (Lepomis cyanellus). General and Comparative Endocrinology 129 56-62.

Manzon LA 2002 The role of prolactin in fish osmoregulation: a review. General and Comparative Endocrinology 125 291-310.

Mustonen AM, Nieminen P \& Hyvarinen H 2002 Leptin, ghrelin, and energy metabolism of the spawning burbot (Lota lota, L.). Journal of Experimental Zoology 293 119-126.

Nagasaka R, Okamoto N \& Ushio H 2006 Increased leptin may be involved in the short life span of ayu (Plecoglossus altivelis). Journal of Experimental Zoology 305A 507-512.

Nishioka RS, Kelley KM \& Bern HA 1988 Control of prolactin and growth hormone secretion in teleost fishes. Zoological Science 5 267-280.

Nonaka S, Hashizume T \& Yamashita T 2006 Effects of leptin and leptin peptide amide on the release of luteinizing hormone, growth hormone and prolactin from cultured porcine anterior pituitary cells. Animal Science Journal 77 47-52.

Peyon P, Zanuy S \& Carrillo M 2001 Action of leptin on in vitro luteinizing hormone release in the European sea bass (Dicentrarchus labrax). Biology of Reproduction 65 1573-1578.

Peyon P, de Celis SVR, Gomez-Requeni P, Zanuy S, Perez-Sanchez J \& Carrillo M 2003 In vitro effect of leptin on somatolactin release in the European sea bass (Dicentrarchus labrax): dependence on the reproductive status and interaction with NPY and GnRH. General and Comparative Endocrinology 132 284-292.

Popovic V \& Duntas LH 2005 Brain somatic cross-talk: ghrelin, leptin and ultimate challengers of obesity. Nutritional Neuroscience 8 1-5.

Riley LG, Hirano T \& Grau EG 2002 Rat ghrelin stimulates growth hormone and prolactin release in the tilapia, Oreochromis mossambicus. Zoological Science 19 797-800.

Sahu A 2004 Leptin signaling in the hypothalamus: emphasis on energy homeostasis and leptin resistance. Frontiers in Neuroendocrinology 24 225-253.

Sangiao-Alvarellos S, Arjona FJ, Miguez JM, del Rio MPM, Soengas JL \& Mancera JM 2006 Growth hormone and prolactin actions on osmoregulation and energy metabolism of gilthead sea bream (Sparus auratus). Comparative Biochemistry and Physiology, Part A 144 491-500.
Sheridan MA 1986 Effects of thyroxin, cortisol, growth hormone, and prolactin on lipid metabolism of coho salmon, Oncorhynchus kisutch, during smoltification. General and Comparative Endocrinology 64 220-238.

Silverstein JT \& Plisetskaya EM 2000 The effects of NPY and insulin on food intake regulation in fish. American Zoologist 40 296-308.

Smith GD, Jackson LM \& Foster DL 2002 Leptin regulation of reproductive function and fertility. Theriogenology 57 73-86.

Tipsmark CK, Weber GM, Strom CN, Grau EG, Hirano T \& Borski RJ 2005 Involvement of phospholipase $\mathrm{C}$ and intracellular calcium signaling in the gonadotropin-releasing hormone regulation of prolactin release from lactotrophs of tilapia (Oreochromis mossambicus). General and Comparative Endocrinology 142 227-233.

Volkoff H, Eykelbosh AJ \& Peter RE 2003 Role of leptin in the control of feeding of goldfish Carassius auratus: interactions with cholecystokinin, neuropeptide Y and orexin A, and modulation by fasting. Brain Research 972 90-109.

Watanobe H 2002 Leptin directly acts within the hypothalamus to stimulate gonadotropin-releasing hormone secretion in vivo in rats. Journal of Physiology 545 255-268.

Watanobe H, Schiöth HB, Wikberg JES \& Suda T 1999 The melanocortin 4 receptor mediates leptin stimulation of luteinizing hormone and prolactin surges in steroid-primed ovariectomized rats. Biochemical and Biophysical Research Communications 257 860-864.

Weil C, Le Bail PY, Sabin N \& Le Gac F 2003 In vitro action of leptin on FSH and $\mathrm{LH}$ production in rainbow trout (Onchorynchus mykiss) at different stages of the sexual cycle. General and Comparative Endocrinology 130 2-12.

Yu WH, Kimura M, Walczewska A, Karanth S \& McCann SM 1997 Role of leptin in hypothalamic-pituitary function. PNAS 94 1023-1028.

Zhang Y, Proenca R, Maffei M, Barone M, Leopold L \& Friedman JM 1994 Positional cloning of the mouse obese gene and its human homologue. Nature 372 425-432.

Zieba DA, Amstalden M, Morton S, Gallino JL, Edwards JF, Harms PG \& Williams GL 2003 Effects of leptin on basal and GHRH-stimulated GH secretion from the bovine adenohypophysis are dependent upon nutritional status. Journal of Endocrinology 178 83-89.

Received in final form 22 October 2007

Accepted 1 November 2007

Made available online as an Accepted Preprint

1 November 2007 